\title{
Efeitos do Arsenito na Meiose, no Desenvolvimento Embrionário Pré-implantação e na Apoptose
}

\section{Embrionária de Camundongos}

\author{
Effects of Arsenite on Meiosis, Preimplantation Development and Apoptosis in the Mouse
}

Autora: Paula Andrea de Albuquerque Salles Navarro

Orientador: Prof. Dr. Rui Alberto Ferriani

Tese de Doutorado apresentada ao Departamento de Ginecologia e Obstetrícia da Faculdade de Medicina de Ribeirão Preto, da Universidade de São Paulo, para obtenção do título de Doutor em Tocoginecologia, em 17 de fevereiro de 2003.

Objetivo: como previamente identificamos efeitos deletérios do comprometimento da função mitocondrial e dos radicais livres do oxigênio na oogênese, investigamos os efeitos do arsenito na meiose, no desenvolvimento embrionário pré-implantação e na apoptose embrionária em camundongos.

Material e Métodos: Camundongas com 6 semanas de idade foram tratadas com baixa $(0,16 \mathrm{mg})$ ou média dose de arsenito $(0,32 \mathrm{mg})$, por meio de 7 injeções intraperitoneais, 1 a cada 2 dias, durante 14 dias. Os controles foram injetados com solvente. A incidência de anomalias meióticas, caracterizadas por anormalidades do fuso celular e/ou mal alinhamento cromossômico, foi significantemente aumentada tanto nos oócitos in vivo ovulados, como nos in vitro maturados, oriundos dos animais tratados com arsenito. Foram detectadas reduções significativas das taxas de clivagem (24 horas de cultivo), de formação de mórula (72 h) e de desenvolvimento para blastocisto (96 h), nos embriões dos grupos tratados com arsenito. Apesar do número total de núcleos não ter diferido significativamente entre os blastocistos dos grupos controle e de tratamento, a percentagem de núcleos apoptóticos foi significantivamente maior nos blastocistos derivados dos animais tratados com a dose média de arsenito.

Conclusões: Estes dados sugerem que o arsenito causa aberrações meióticas, que podem contribuir tanto para o comprometimento do desenvolvimento embrionário pré-implantação, como para a apoptose embrionária.

Palavras-chave: Anomalias meióticas. Desenvolvimento embrionário. Apoptose.

\section{RBCO $26(3): 256,2004$}

Resumo de Tese

\section{Análise Multivariada dos Fatores de Risco Anteparto para Ocorrência de Cesárea}

\section{Multivariate Analysis of Antepartum Risk for the Occurrence of Cesarean Section}

Autora: Simone Angélica Leite de Carvalho Silva Cabral

Orientador: Prof. Dr Cícero Ferreira Fernandes Costa

Dissertação de Mestrado apresentada à Faculdade de Ciências Médicas - Programa de Mestrado em Tocoginecologia - Universidade de Pernambuco, em 4 de fevereiro de 2003.

Objetivo: avaliar fatores intervenientes anteparto para operação cesariana na Maternidade Professor Monteiro de Morais - CISAM, no período de 01 de setembro de 1999 a 31 de agosto de 2000, através de modelo logístico multivariado epidemiológico.

Métodos: realizou-se um estudo longitudinal, retrospectivo, epidemiológico, do tipo caso-controle com 3.626 gestantes. A partir da caracterização da via de parto em dois grupos: caso (parturientes submetidas à cesárea) e controle (submetidas ao parto vaginal), por análise bivariada determinou-se associação das variáveis independentes com a via de parto. Através de análise logística multivariada foi determinado modelo preditivo, consideradas as variáveis independentes: antecedente de parto cesáreo restrito a um, antecedente de parto vaginal, assistência pré-natal, primiparidade, gemelaridade, idade gestacional, idade materna, sindrome hipertensiva, diabetes mellitus, síndrome hemorrágica, oligoâmnio e rotura prematura de membranas.

Resultados: na análise bivariada todas as variáveis independentes se associaram à cesárea, exceto idade materna e gestação pré-termo. O risco basal de cesárea igualou-se a $15,2 \%$ e a concordância entre o previsto pela equação logística e cesárea realizada a $86,6 \%$.

Conclusões: Foram identificados como fatores de risco para cesárea: antecedente de parto cesáreo, assistência pré-natal incompleta, gemelaridade, gestação póstermo, idade materna entre 20 e 34 anos ou igual ou superior a 35 anos, presença de sindrome hipertensiva, de diabetes mellitus, de síndrome hemorrágica, de oligoâmnio e de rotura prematura de membranas. O antecedente de parto vaginal e idade inferior a 19 anos foram fatores de proteção.

Palavras-chave: Parto normal. Cesárea. Pré-natal. Prematuridade. 